\title{
Two-Triangle Carrier SPWM Modulation For a Five-Level Diode-Clamped PWM Inverter
}

\author{
Natchpong Hatti* Non-member, Surasak Nuilers* Non-member \\ Jirayut Phontip* Non-member
}

(Manuscript received Feb. 20, 2014, revised June 23, 2014)

\begin{abstract}
This paper describes two-triangle carrier sinusoidal pulse-width-modulation (SPWM) for a five-level diode-clamped PWM inverter and compares it to the SPWM-based neutral-point-clamped (NPC) PWM inverter and the original SPWM-based five-level diode-clamped PWM inverter for use in medium-voltage motor drives. The characteristics of the three techniques are compared by analysis and experiment for an adjustable-speed motor drive for pumps and blowers without a transformer. The experimental systems are $380-\mathrm{V} 5.5-\mathrm{kW}$ downscale models. The experimental systems were designed, constructed, and tested for the comparison study and were based on a 16-bit digital signal processor with the use of insulated gate bipolar transistors as switching devices. A $5.5-\mathrm{kW}$ four-pole induction motor coupled with a permanent-magnet synchronous generator was used as the electrical load.
\end{abstract}

Keywords: five-level diode-clamped PWM inverter, level-shifted PWM, medium-voltage drives, neutral-point-clamped PWM inverter, sinusoidal PWM, voltage-balancing circuit

\section{Introduction}

Among the high-power converters used in medium-voltage applications (in the range of 2.3 to $6.6 \mathrm{kV}$ ), the three-level diode-clamped PWM inverter, the so-called "neutral-pointclamped (NPC) PWM inverter", has been the most widely used in various industrial applications such as static synchronous compensator, motor drives, battery energy storage systems, etc. ${ }^{(1)-(6)}$ The benefits of the NPC PWM inverters are their simple structure, their common dc-link configuration that makes it possible to share a dc-link network such as in the applications of back-to-back and multi drive systems, they can operate in a grid friendly fashion with additional power filters or higher pulse rectifiers (12-Pulse and higher), they have excellent dynamic behavior, and their dc-link capacitor voltages can be simply balanced by costless means such as a sixth harmonic zero sequence or dc zero sequence injection ${ }^{(7)-(11)}$. However, for higher power and higher voltage applications, one needs higher voltage rating switching devices that may not be available in the market. Although we can connect the switching devices in series to achieve higher voltage capability ${ }^{(2)(12)-(14)}$, we still experience the problems of high dv/dt output voltage, high output voltage step, and high Electromagnetic Interference (EMI). Moreover, the gate drivers for the series connected switching devices are complex. Therefore, higher voltage levels of inverters have become more interesting because they can use the switching devices available in the market, have lower $\mathrm{dv} / \mathrm{dt}$, and less of an EMI problem ${ }^{(4)(6)}$. This paper studies a five-level diode-clamped PWM inverter because it has some benefits in

\footnotetext{
* National Electronics and Computer Technology Center, National Science and Technology Development Agency

112, Thailand Science Park, Phahonyothin Road, Klong Nueng, Klong Luang, Pathumthani, 12120, Thailand 112
}

common with the NPC, but has a higher power capability.

However, the main problem of the higher voltage levels diode-clamped PWM inverters is the unbalancing of the dclink capacitor voltages, which is difficult to solve without the following drawbacks: reducing the inverter performance, increasing the system cost, and increasing power losses. Many researchers have been paying attention to solving the dc-link capacitor voltage unbalancing of the higher voltage levels of the diode-clamped PWM inverters (with voltage levels higher than three). The existing voltage-balancing techniques can be categorized into two groups: hardware ${ }^{(15)-(21)}$ and control ${ }^{(22)-(26)}$ techniques.

The hardware techniques can be categorized into two groups as follows: 1) Connecting the inverter in the configuration of a back-to-back system ${ }^{(17)}$. A back-to-back system consists of two inverters. One inverter is connected at the point of common coupling of the utility grid, while the other one is connected to the load or motor. The two inverters share the dc-link network. Since the current directions of the two inverters are opposite, the dc mean currents that flow into or out of the dc-link capacitors can be cancelled by the operation of the two inverters. This can help balance the dc-link capacitor voltages. This technique requires a control technique for an effective dc-link capacitor voltage balance. 2) Adding auxiliary circuits as voltage-balancing circuits to the dc-link network to achieve capacitor voltage balance ${ }^{(15)(18)-(21)}$. This technique uses voltage-balancing circuits to control the balance of the dc-link capacitor voltages. Moreover, the authors of (20) and (21) proposed improvements reducing the size of the voltage-balancing circuits. In addition, some researchers have reconfigured the diode-clamped PWM inverter $^{(16)}$ to achieve dc-link capacitor voltage balance.

Generally, the main benefits of hardware techniques are that the dc-link capacitor voltages are well balanced for the 
whole operating range of the inverter and do not affect the inverter's performance. However, their drawbacks are a higher system cost, lower reliability (because having more parts), requiring space to install, and the power losses of the voltagebalancing circuits cannot be neglected.

For the control techniques, mainly they use redundant switch states of the inverters to balance the dc-link capacitor voltages ${ }^{(25)(26)}$. The inverters are not only for driving the output load, but also for balancing the dc-link capacitor voltages using redundant switch states. Therefore, the benefits of control techniques are lower system cost, greater reliability, and not requiring any additional space to install. However, their drawbacks are that it is difficult to balance the dc-link capacitor voltages for the whole operating range of the inverter $^{(27)}$, they affect the inverter's performance-especially the total harmonic distortion of the inverter's output voltage waveform, and the switching loss may be extremely high.

This paper introduces a new modulation technique for the five-level diode-clamped PWM inverter ${ }^{(28)(29)}$ that can significantly reduce the power rating of the voltage-balancing circuits. Because the proposed technique has some characteristics in common with an NPC inverter and the original fivelevel diode-clamped inverter, a comparison of the new technique with the NPC inverter and with the original five-level diode-clamped inverter is also presented in this paper. This paper is organized as follows: Section 2 reviews the characteristics of the NPC and the original five-level diode-clamped PWM inverters. Section 3 explains the new modulation technique. Section 4 compares the characteristics of the three inverter topologies by analysis and experiment. The system is mainly intended for energy-saving use when applied to pumps and blowers, which are the majority of the motor drives in all industrial applications ${ }^{(3)}$. Finally, Section 5 concludes the paper.

\section{The SPWM-Based NPC and the Original SPWM-Based Five-Level Diode-Clamped In- verters}

Figure 1(a) is a basic diagram of the NPC PWM inverter intended for use in higher power and higher voltage applications. It utilizes four switches in one phase leg (T1T4). However, each switch is a series connection of two (or more) switching devices to increase the rated voltage of the switch. In order to achieve an equal voltage-sharing of the series-connected switching devices under both static and dynamic conditions, special gate drivers are required ${ }^{(6)(12)(13)}$. The SPWM of the NPC inverter uses two-triangle carrier signals as described in Fig. 2. The output of the phase voltage reference to the node $\mathrm{M}\left(v_{O-M}\right)$ is a three-level waveform.

Here, the phase inverter voltage reference signals $e^{*}$ and the phase output current $i_{O}$ are sinusoidal, as described below:

$$
e^{*}=\sqrt{2} E \sin (\omega t)
$$

and

$$
i_{O}=\sqrt{2} I \sin (\omega t-\phi) .
$$

Here, $E$ is the rms value of the line-to-neutral output voltage reference and $\mathrm{I}$ is the rms value of the phase output current.

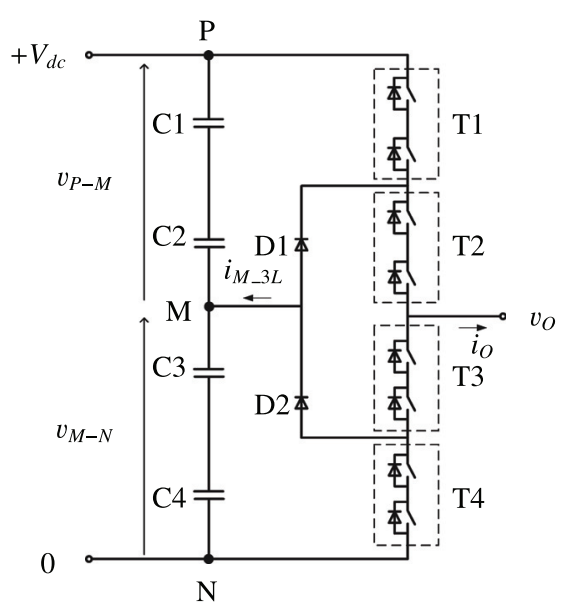

Fig. 1. Single-phase basic diagrams of the NPC PWM inverter intended for use in higher power and higher voltage applications

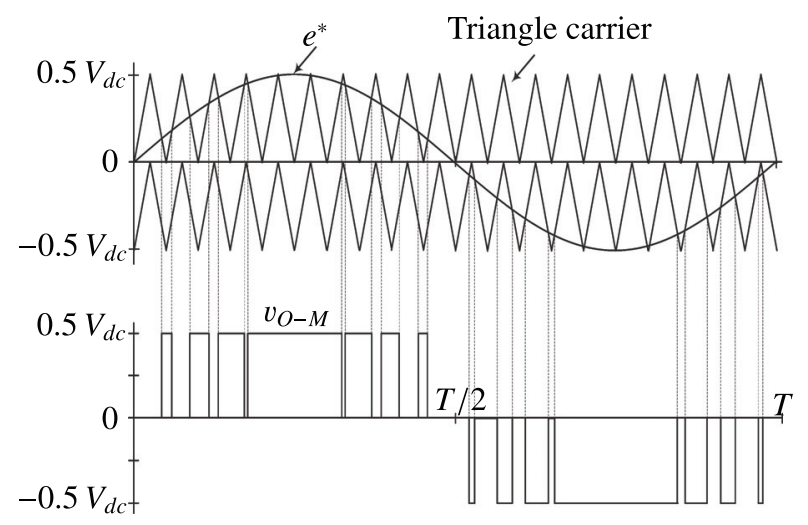

Fig. 2. SPWM modulation signals for the NPC PWM inverter

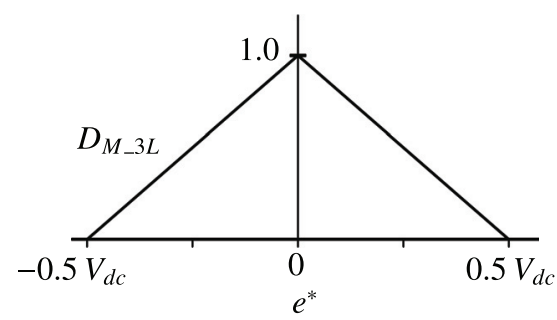

Fig. 3. Duty factor of the NPC PWM inverter

Figure 3 shows the duty factor of the current flowing into or out of the node M of the NPC inverter. Equations 3 and 4 express the duty cycle $D$ and dc mean current $\bar{i}_{M_{-} 3 L}$ (for three-phase system), respectively (assuming the frequency of the PWM triangular carrier is much higher than that of the maximal inverter output frequency). It is clear that, theoretically, the dc mean current flowing into or out of the node $\mathrm{M}$ (or the dc-link capacitors) is zero. Therefore the dc-link capacitor voltages of the NPC inverter are balanced. In practice, unequal power losses in the switching devices and capacitors, quantizing errors of the control signal, etc., may cause a voltage imbalance. Fortunately, this problem can be easily solved by many control techniques such as superimposing a zero sequence, as described in (7)-(11). 


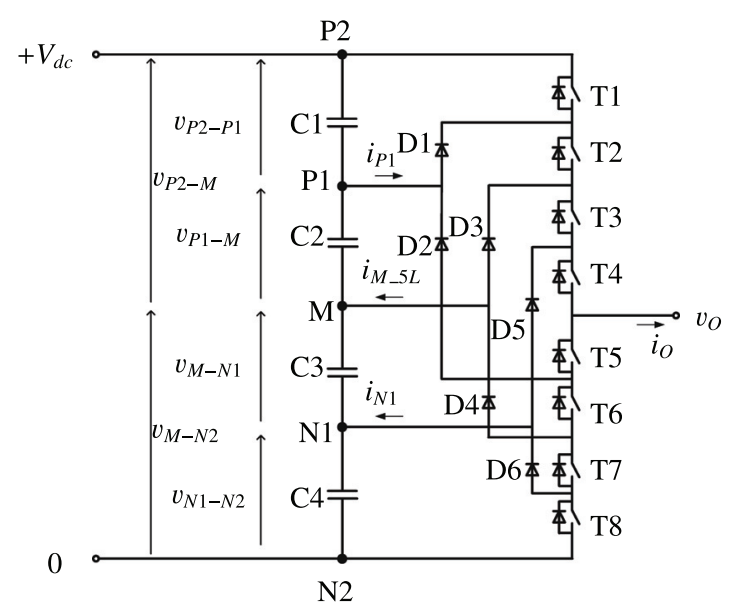

Fig. 4. Single-phase basic diagrams of the five-level diode-clamped PWM inverter

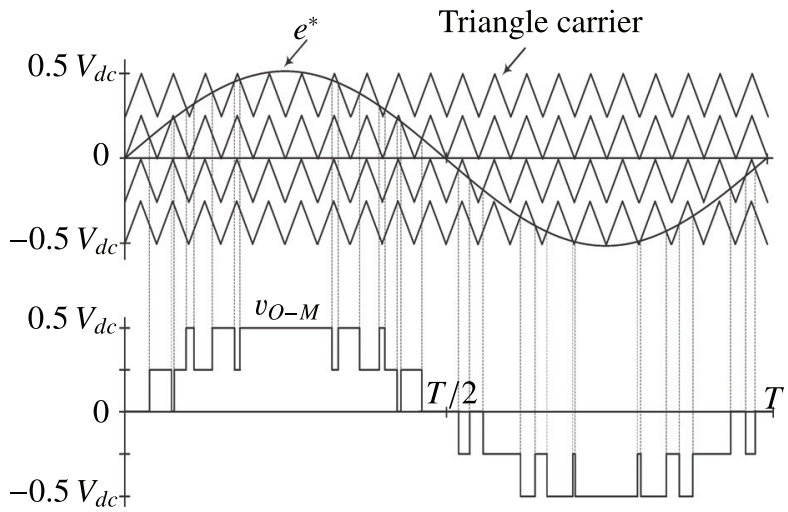

Fig. 5. Original (four-triangle carrier) SPWM modulation signals of the five-level diode-clamped PWM inverter

$$
\begin{aligned}
& D_{M_{-} 3 L}=\left\{\begin{array}{ll}
1+2 e^{*} / V_{d c} & \left(-V_{d c} / 2 \leq e^{*}<0\right) \\
1-2 e^{*} / V_{d c} & \left(0 \leq e^{*}<V_{d c} / 2\right)
\end{array} \ldots \ldots .\right. \\
& \bar{i}_{M \_3 L}=\frac{3}{T} \int_{0}^{T} D_{M \_N P C} i_{O} d t=0 . \cdots \ldots \ldots \ldots \ldots \ldots
\end{aligned}
$$

Figure 4 shows the basic diagram of the five-level diodeclamped PWM inverter. In general, the five-level inverter is more suitable than the NPC inverter for higher voltage and higher power applications because it can use the same voltage rating switching devices as used in an NPC inverter without the problem of unequal voltage sharing. Therefore, the gate drivers of the switching devices (T1-T8) are less complicated than that of the NPC inverter in Fig. 1. Moreover, the quality of the voltages and currents is higher. The general SPWM of the five-level diode-clamped PWM inverter uses four-triangle carrier signals as shown in Fig. 5. The phase output voltage reference to the node $\mathrm{M}\left(v_{O-M}\right)$ is a five-level voltage waveform.

Figure 6 shows the duty factors of the current flowing into or out of the the nodes $\mathrm{M}\left(D_{M_{-} 5 L}\right), \mathrm{P} 1\left(D_{P 1}\right)$, and P2 $\left(D_{P 2}\right)$ of the five-level diode-clamped PWM inverter with the original SPWM. The duty factors are also described in Equations 5 and $6^{(19)}$. The behavior of the current flowing into the node $\mathrm{M}$ is the same as in the case of the NPC inverter. Therefore, the solution for balancing the mid-point voltage of the NPC

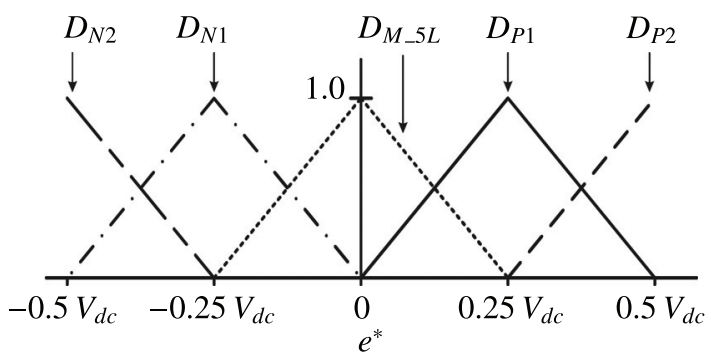

Fig. 6. Duty factors of the original SPWM based fivelevel diode-clamped PWM inverter

and that of the five-level diode-clamped PWM inverters is the same (the mid-point voltage is the difference between the voltage $v_{P-M}$ and the voltage $v_{M-N}$ of the NPC inverter, or the voltage difference between the voltage $v_{P 2-M}$ and the voltage $v_{M-N 2}$ of the five-level inverter.). For the duty cycles of the dc mean currents flowing into the nodes P1 and N1 of the fivelevel inverter, we can see that they are not zero. This results in the dc-link capacitor voltages (the voltages between $v_{P 1-M}$ and $v_{P 2-P 1}$ and the voltage between $v_{M-N 1}$ and $v_{N 1-N 2}$ ) being unbalanced. The solutions for this problem are as mentioned in $^{(15)-(21)}$.

$$
\begin{gathered}
D_{P 1}= \begin{cases}0 & \left(e^{*}<0\right), \\
4 e^{*} / V_{d c} & \left(0 \leq e^{*}<V_{d c} / 4\right), \\
2-4 e^{*} / V_{d c} & \left(V_{d c} / 4 \leq e^{*}<V_{d c} / 2\right), \\
0 & \left(V_{d c} / 2 \leq e^{*}\right) .\end{cases} \\
D_{M_{-} 5 L}= \begin{cases}0 & \left(e^{*}<-V_{d c} / 4\right) \\
1+4 e^{*} / V_{d c} & \left(-V_{d c} / 4 \leq e^{*}<0\right) \\
1-4 e^{*} / V_{d c} & \left(0 \leq e^{*}<V_{d c} / 4\right) \\
0 & \left(V_{d c} / 4 \leq e^{*}\right) .\end{cases}
\end{gathered}
$$

The dc mean current $\bar{i}_{P 1}$ (for three-phase system) in steady state can be defined as the average value of the instantaneous current flowing into the node P1 over a period of the inverter output cycle $T$. It has been proven that only the active current affects the dc mean current $\bar{i}_{P 1}{ }^{(19)(27)}$. Therefore, $\bar{i}_{P 1}$ is given by

$$
\bar{i}_{P 1}=\frac{3}{T} \int_{0}^{T} D_{P 1} i_{O} d t=\frac{6}{T} \int_{0}^{\frac{T}{4}} D_{P 1} i_{a c t} d t, \cdots \cdots \cdots
$$

where

$$
i_{a c t}=\sqrt{2} I_{a c t} \sin (\omega t)
$$

and $I_{a c t}$ is the rms value of the phase output active current.

The dc mean current $\bar{i}_{P 1}$ directly defines the dc mean current flowing into or out of the voltage balancing circuit $\left(\bar{i}_{P}\right)$. This means the higher is $\bar{i}_{P 1}$, the higher is the required power rating of the voltage balancing circuits. It should be noted that the dc mean currents of the nodes $\mathrm{P} 1\left(i_{P 1}\right)$ and $\mathrm{N} 1\left(i_{N 1}\right)$ are theoretically equal. Therefore, for the sake of simplicity, the duty cycle and currents of the node $\mathrm{N} 1$ will not be treated in detail.

\section{The Two-Triangle Carrier SPWM}

This paper introduces a two-triangle carrier SPWM for the five-level diode-clamped inverter. This technique reduces the time spent on the voltage levels of $\pm 0.25 \mathrm{Vdc}$. It uses the voltage levels $\pm 0.25 \mathrm{Vdc}$ only for maintaining the voltage level 


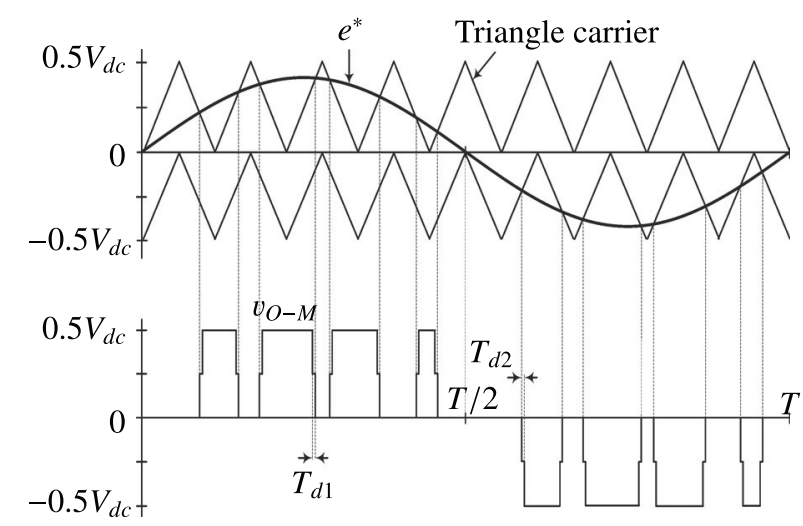

Fig. 7. The two-triangle carrier SPWM modulation signals for the five-level diode-clamped PWM inverter

Table 1. Switching states of the five-level diodeclamped PWM inverter with two-carrier modulation

\begin{tabular}{c||c||c|c|c|c|c|c|c|c}
\hline \multicolumn{1}{c||}{ Output voltage $\left(v_{O-M}\right)$} & Pulse width & \multicolumn{7}{c}{ Switching states } \\
\cline { 3 - 9 } & adjustment & $\mathrm{T} 1$ & $\mathrm{~T} 2$ & $\mathrm{~T} 3$ & $\mathrm{~T} 4$ & $\mathrm{~T} 5$ & $\mathrm{~T} 6$ & $\mathrm{~T} 7$ & $\mathrm{~T} 8$ \\
\hline \hline$+0.5 \mathrm{~V}_{\mathrm{dc}}$ & PWM & $\mathrm{H}$ & $\mathrm{H}$ & $\mathrm{H}$ & $\mathrm{H}$ & $\mathrm{L}$ & $\mathrm{L}$ & $\mathrm{L}$ & $\mathrm{L}$ \\
$+0.25 \mathrm{~V}_{\mathrm{dc}}$ & Fixed at $T_{d 1}$ & $\mathrm{~L}$ & $\mathrm{H}$ & $\mathrm{H}$ & $\mathrm{H}$ & $\mathrm{H}$ & $\mathrm{L}$ & $\mathrm{L}$ & $\mathrm{L}$ \\
0 & PWM & $\mathrm{L}$ & $\mathrm{L}$ & $\mathrm{H}$ & $\mathrm{H}$ & $\mathrm{H}$ & $\mathrm{H}$ & $\mathrm{L}$ & $\mathrm{L}$ \\
$-0.25 \mathrm{~V}_{\mathrm{dc}}$ & Fixed at $T_{d 2}$ & $\mathrm{~L}$ & $\mathrm{~L}$ & $\mathrm{~L}$ & $\mathrm{H}$ & $\mathrm{H}$ & $\mathrm{H}$ & $\mathrm{H}$ & $\mathrm{L}$ \\
$-0.5 \mathrm{~V}_{\mathrm{dc}}$ & PWM & $\mathrm{L}$ & $\mathrm{L}$ & $\mathrm{L}$ & $\mathrm{L}$ & $\mathrm{H}$ & $\mathrm{H}$ & $\mathrm{H}$ & $\mathrm{H}$ \\
\hline & \multicolumn{6}{c|}{ Note: L mon turn off. H means turn on. }
\end{tabular}

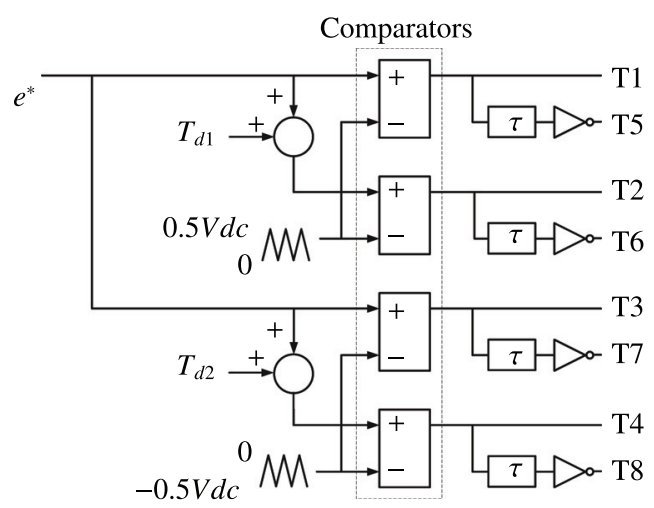

Fig. 8. Two-triangle carrier modulation diagram for the five-level diode-clamped PWM inverter

at five. This results in an extremely low flow of the dc mean current into or out of the nodes P1 and N1. Then, we can use tiny voltage balancing circuits that do not affect the cost and size of the system. The two-triangle carrier SPWM signals are shown in Fig. 7. Table 1 summarizes the switching states of T1-T8 of the two-triangle carrier signal modulation. From Fig. 1 and Table 1, it is clear that the voltage level and number of switching states are the same as the original SPWM ${ }^{(6)}$. However, the pulse widths at the voltage level $\pm 0.25 \mathrm{Vdc}$ are fixed. Figure 8 shows the two-triangle carrier modulation diagram for the five-level inverter. Since the voltage levels of $0.25 \mathrm{Vdc}$ and $-0.25 \mathrm{Vdc}$ are fixed with small pulse widths ( $T_{d 1}$ and $T_{d 2}$, respectively), the output voltage looks like a three-level waveform. However, the actual voltage level is five. $\tau$ is used for setting the dead time of the corresponding switching devices for the prevention of shoot through. Using the two-triangle carrier SPWM, the switching frequency of each switch is fixed at $f_{C} / 2$ for the whole inverter's operating range (the same as the NPC inverter).

Figure 9 and Equations 9 and 11 show the duty cycles

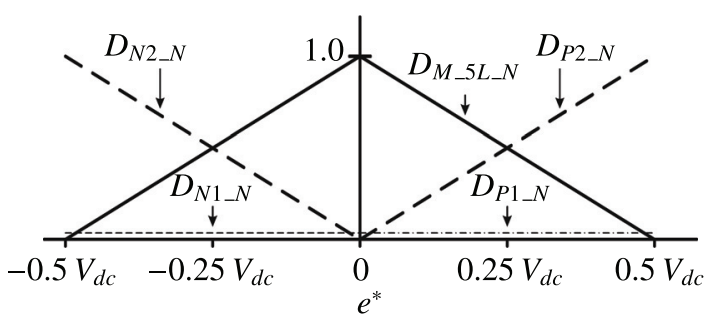

Fig. 9. Duty factors of the two-triangle carrier SPWM based five-level diode-clamped PWM inverter

of the five-level diode-clamped PWM inverter with the twotriangle carrier SPWM. The dc mean current flowing into or out of the voltage balancing circuit can be determined by the duty factor of the nodes P1 $\left(D_{P 1 \_N}\right)$ and the dc mean current flowing into or out of the node P1 $\left(\bar{i}_{P 1 \_N}\right)$. It should be noted that the actual dc mean current flowing into or out of the voltage-balancing circuits would be higher than those resulting from this analysis, which excludes consideration of the power losses.

The duty factor $\left(D_{P 2 \_N}\right)$ and the dc mean current of the node P2 $\left(\bar{i}_{P 2 \_N}\right)$ for three-phase system are given by

$$
D_{P 2 \_N}= \begin{cases}0 & \left(e^{*}<0\right) \\ 2 e^{*} / V_{d c} & \left(0 \leq e^{*}<V_{d c} / 2\right) \\ 1 & \left(V_{d c} / 2 \leq e^{*}\right)\end{cases}
$$

and

$$
\bar{i}_{P 2 \_N}=\frac{6}{T} \int_{0}^{\frac{T}{4}} D_{P 2 \_N} i_{a c t} d t . \cdots \ldots \ldots \ldots \ldots \ldots \ldots
$$

Assuming the ratio between $T_{d 1}$ and $T$ is much less than $D_{P 2 \_N}$, the duty factor and the dc mean current of the node $\mathrm{P} 1$ are given by

$$
D_{P 1 \_N}=\frac{T_{d 1}}{T}
$$

and

$$
\bar{i}_{P 1 \_N}=\frac{6}{T} D_{P 1 \_N} \int_{0}^{\frac{T}{4}} D_{P 2 \_N} i_{a c t} d t . \cdots \cdots \cdots \cdots \cdots
$$

\section{A Comparison Study By Simulation And Ex- periment}

The passive front-end inverter systems shown in Fig. 10 and Fig. 11 are used for a comparison study. The system in Fig. 10 is based on the NPC PWM inverter, while that in Fig. 11 is based on the five-level diode-clamped PWM inverter. Figure 11 can be considered as either the original or two-triangle carrier SPWM five-level diode-clamped inverter. The voltage-balancing circuits based on buck and boost converters are connected to the dc-link network of the five-level inverter to balance the dc-link capacitor voltages: the buck converter is used for balancing the voltage between $v_{P 2-P 1}$ and $v_{P 1-M}$ and the boost converter is used for balancing the voltages between $v_{M-N 1}$ and $v_{N 1-N 2}$. The mid-point voltages of both the NPC and five-level inverters are controlled by injecting the dc zero sequence ${ }^{(20)}$. All systems have a power rating of $5.5 \mathrm{~kW}$ and $380 \mathrm{~V}$ input voltage. The carrier frequency of the inverters $\left(f_{C}\right)$ is $2.5 \mathrm{kHz}$. The carrier frequency of the voltage balancing circuits is $5 \mathrm{kHz}$. The inductors $\left(L_{P}\right.$ 


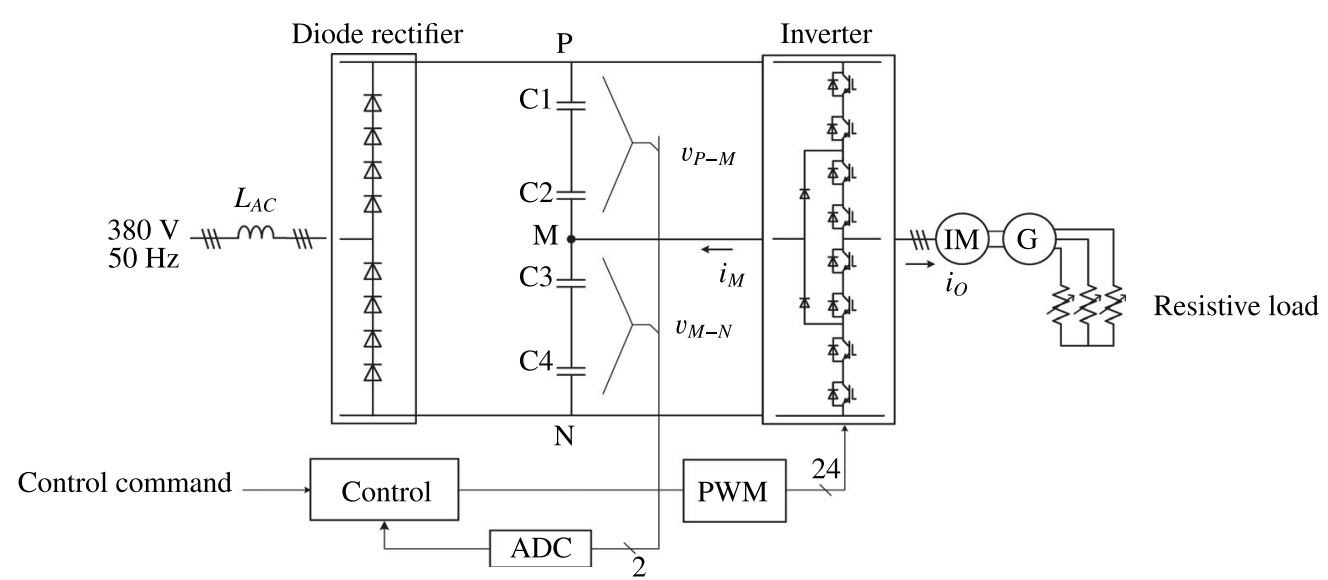

Fig. 10. Passive front-end NPC PWM inverter system for motor drives

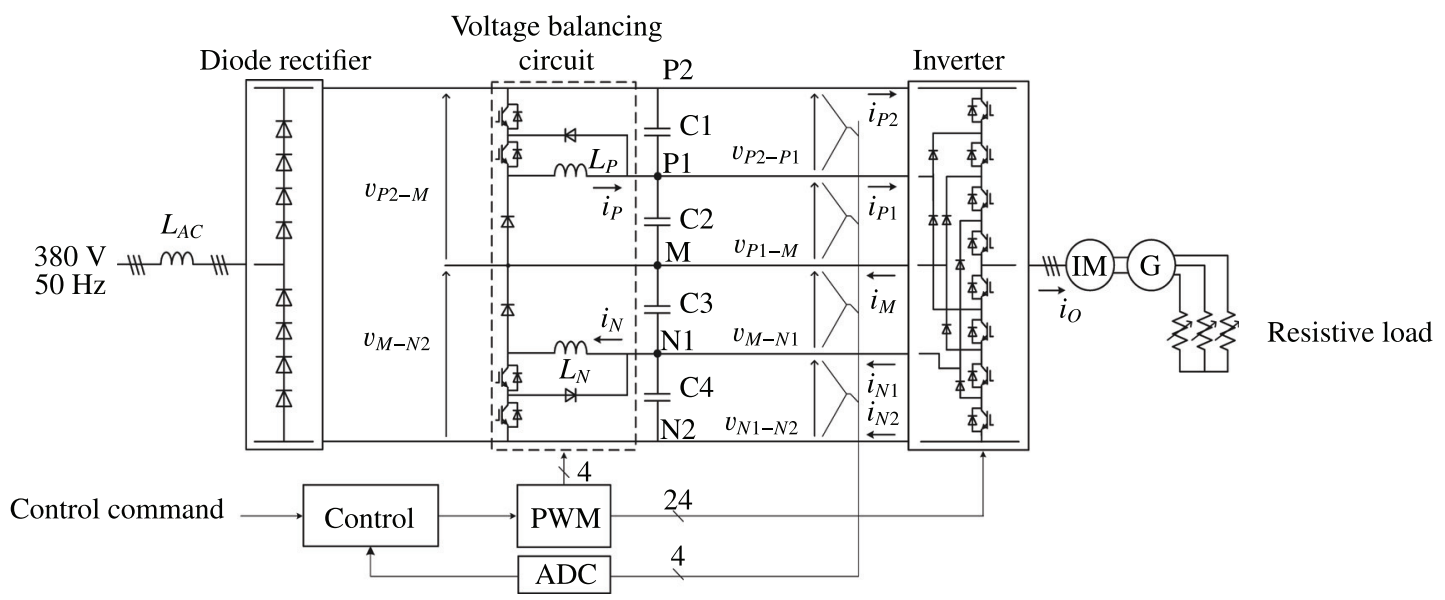

Fig. 11. Passive front-end five-level diode-clamped PWM inverter system for motor drives

Table 2. Ratings and circuit parameters

\begin{tabular}{lr||c}
\hline Power rating & $5.5 \mathrm{~kW}$ \\
\hline Rated ac voltage & $380 \mathrm{~V}$ \\
\hline Rated motor current & $V_{d c}$ & $130 \mathrm{~V}$ \\
\hline dc capacitor voltage & $C_{d c}$ & $4.7 \mathrm{mF}$ \\
\hline Split dc capacitor & $V_{d c}$ & $520 \mathrm{~V}$ \\
\hline Dc link voltage & $H$ & $29 \mathrm{~ms}($ at $520 \mathrm{Vdc})$ \\
\hline Unit capacitance constant ${ }^{(8)}$ & $f_{C}$ & $2.5 \mathrm{kHz}$ \\
\hline Carrier frequency of the inverters & $5 \mu \mathrm{s}$ \\
\hline$T_{d 1}$ and $T_{d 2}$ & $10 \mathrm{mH}, 3 \mathrm{~A}$ \\
\hline$L_{P}$ and $L_{N}$ & \\
for original SWPM & $150 \mathrm{mH}, 0.2 \mathrm{~A}$ \\
\hline $\begin{array}{l}L_{P} \text { and } L_{N} \\
\text { for two-triangle carrier SPWM }\end{array}$ & \\
\hline Carrier frequency of the voltage- & $5 \mathrm{kHz}$ \\
balancing circuits & \\
\hline
\end{tabular}

and $L_{N}$ ) of the voltage balancing circuit of the original and two-triangle carrier SPWM five-level diode-clamped inverters are $10 \mathrm{mH} 3 \mathrm{~A}$ and $150 \mathrm{mH} 0.2 \mathrm{~A}$, respectively. The load is a four-pole $5.5-\mathrm{kW}$ induction motor coupled with a $5.5-\mathrm{kW}$ permanent magnet synchronous generator with three-phase resistive load.

The motor drive systems in this paper are intended for energy savings for pumps and blowers. The motor speed generally is adjusted within a limited range, say from one-half

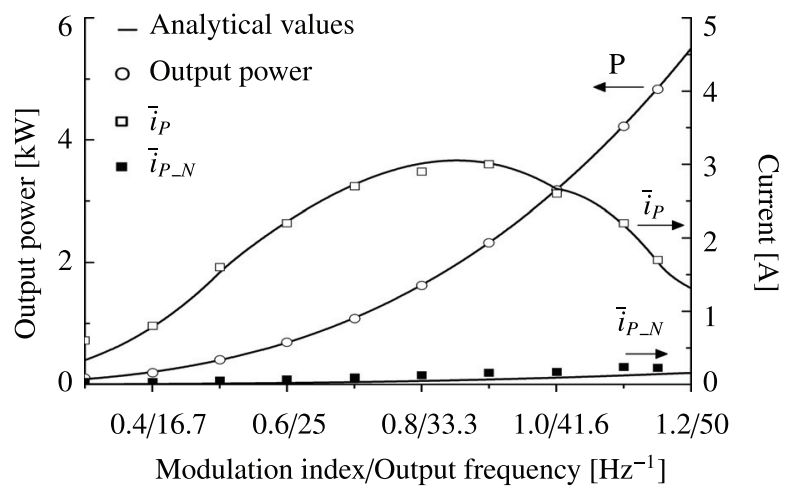

Fig. 12. Output power and dc mean currents of the node $\mathrm{P} 1$ and of the voltage-balancing circuit for the five-level inverters, where $i_{P 1}$ equals $i_{P}$ and $i_{P 1_{N}}$ equals $i_{P_{N}}$

speed to top speed. Moreover, the output power is proportional to the cube of the rotating speed. Therefore, the threephase resistive load in Fig. 10 and Fig. 11 is adjusted to make the motor produce the output power required by a pump/blower-like load.

In Fig. 12, the analytical and experimental results of the output power $(P)$, and the dc mean currents of the voltage balancing circuit (the buck converter) $\left(\bar{i}_{P}\right.$ and $\left.\bar{i}_{P_{-} N}\right)$ of the fivelevel inverters are compared with the original SPWM and the two-triangle carrier SPWM. We can see that the maximum value of the dc mean current flowing into or out of the voltage 


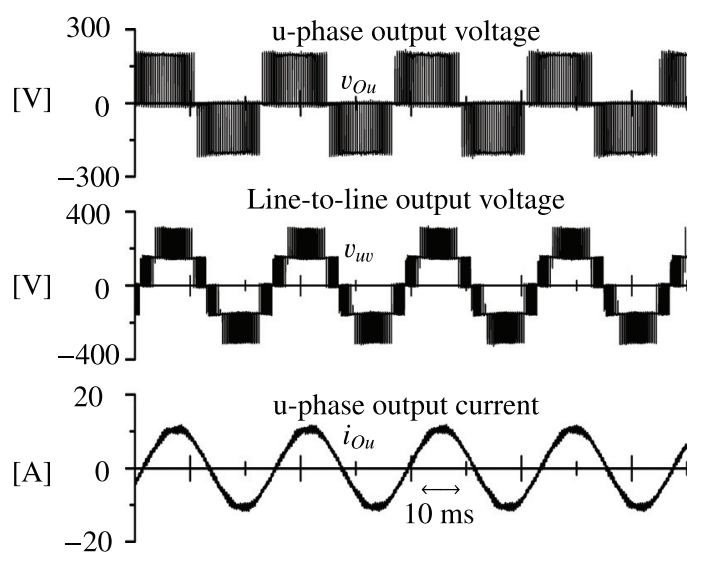

Fig. 13. Experimental waveforms of the NPC PWM inverter when the modulation index was 1.0 , output power was $3.2 \mathrm{~kW}$, and output frequency was $41.6 \mathrm{~Hz}$

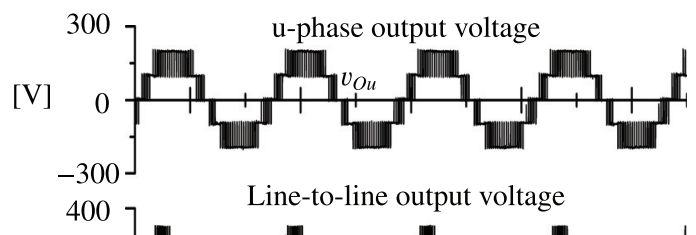

[V]
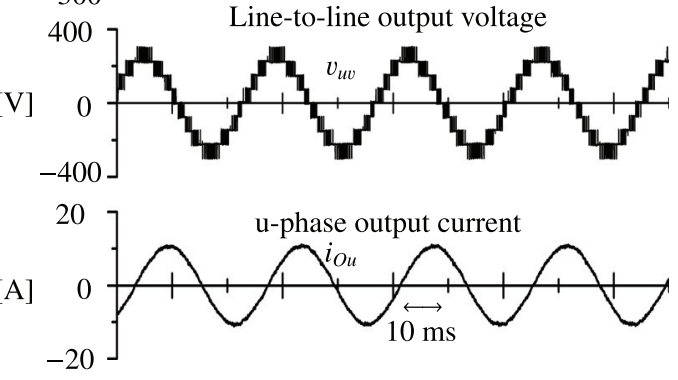

Fig. 14. Experimental waveforms of the original SPWM based five-level diode-clamped PWM inverter when the modulation index was 1.0 , output power was $3.2 \mathrm{~kW}$, and output frequency was $41.6 \mathrm{~Hz}$

balancing circuits of the two-triangle carrier SPWM is $0.2 \mathrm{~A}$ (power rating is $26 \mathrm{~W}$ ), whereas of the original SPWM is $3 \mathrm{~A}$ (power rating is $390 \mathrm{~W}$ ). The size of the voltage balancing circuit with the proposed technique is $0.5 \%$ of the power rating of the motor. This reduces the power conversion loss, initial cost, size, weight, and installation space of the voltage balancing circuits.

Moreover, in practice, the ratio between the delay time $\left(T_{d 1}\right.$ and $T_{d 2}$ ) and the period $T$ is lower than of the experimental system in this paper because of the lower carrier frequency. Therefore, the power rating of the voltage balancing circuits would become smaller. It should be noted that Fig. 12 does not include the results of the NPC inverter because the NPC inverter does not require voltage balancing circuits. In addition, at the modulation index higher than 1.0, the third harmonic injection technique is applied ${ }^{(6)}$.

Figures 13, 14, and 15 show the u-phase output voltage $\left(v_{O u}\right)$, line-to-line voltage $\left(v_{u v}\right)$, and u-phase output current $\left(i_{O u}\right)$ of the NPC, the five-level inverter with original SPWM, and the five-level inverter with the two-triangle carrier SPWM when the modulation index was 1.0, respectively. We can see that the waveforms of the NPC inverter and the five-level inverter with the two-triangle carrier SPWM look similar. However, Fig. 16 expands the time/div of the

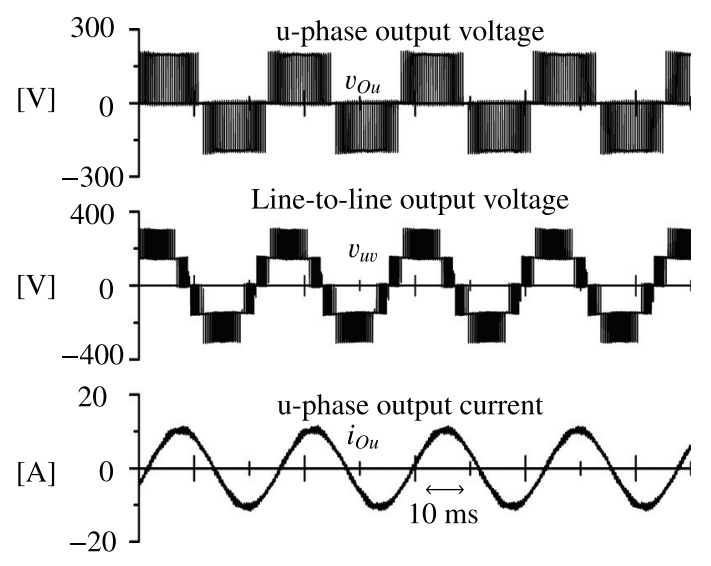

Fig. 15. Experimental waveforms of the two-triangle carrier SPWM based five-level diode-clamped PWM inverter when the modulation index was 1.0 , output power was $3.2 \mathrm{~kW}$, and output frequency was $41.6 \mathrm{~Hz}$

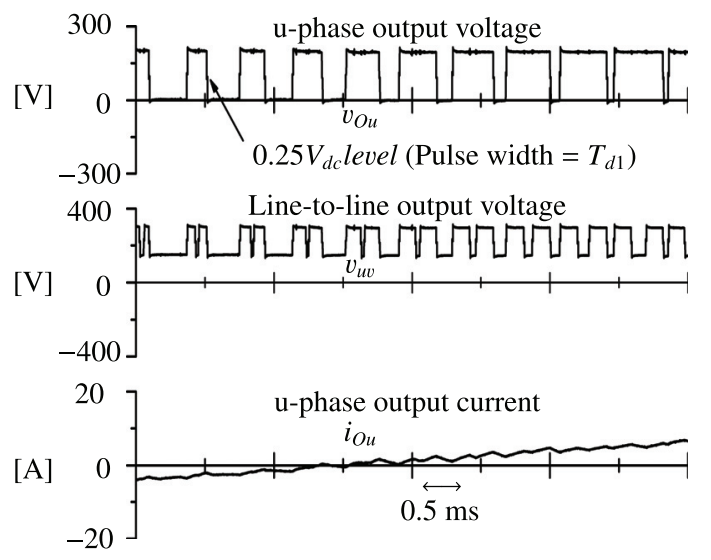

Fig. 16. Time-expanded waveforms in Fig. 15

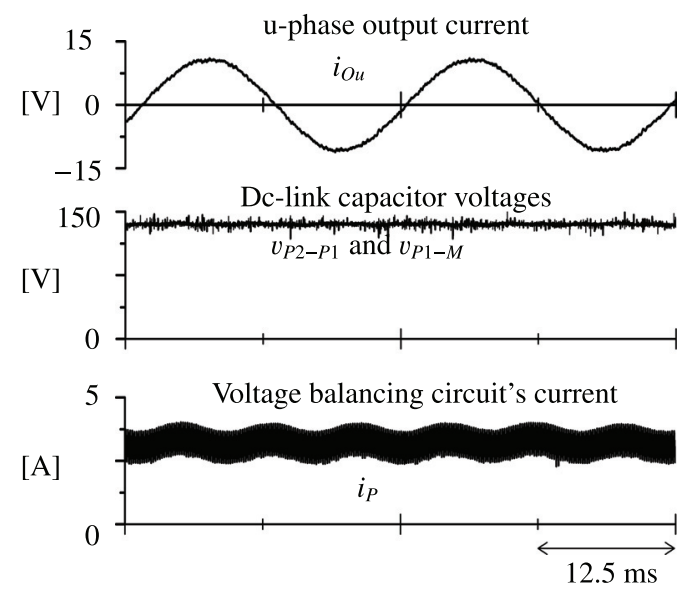

Fig. 17. Experimental waveforms of the voltage balancing circuit (buck converter) with the original SPWM based five-level diode-clamped PWM inverter when the modulation index was 1.0 , output power was $3.2 \mathrm{~kW}$, and output frequency was $41.6 \mathrm{~Hz}$

waveform of Fig. 15 and claims that the voltage level of the proposed modulation technique is five-level.

Figures 17 and 18 show the operating waveforms of the voltage balancing circuit (buck converter) at the modulation index 1.0 when operated with the original SPWM based five-level inverter and two-triangle carrier SPWM five-level 
inverter, respectively. The dc-link capacitor voltages $v_{P 2-P 1}$ and $v_{P 1-M}$ in Figs. 17 and 18 have the average values of $134 \mathrm{~V}$ and $133 \mathrm{~V}$, respectively. The voltage error of the dc-link capacitor voltages in both cases is less than $\pm 1 \%$. The dc mean current with original $\operatorname{SPWM}\left(i_{P}\right)$ is $2.6 \mathrm{~A}$, whereas the dc mean current with two-triangle carrier SPWM $\left(i_{P}\right)$ is only $0.17 \mathrm{~A}$. The behavior of the boost converter and the corresponding voltages and currents are not different from those of the buck converter. Therefore, its results are not shown in detail.

Figure 19 compares the line-to-line voltage harmonics and total harmonic distortion (THD) of the experimental systems. The harmonics and THD of the voltage of the five-level inverter with the original SPWM are the lowest. The harmonics and THD of the NPC inverter and the five-level inverter with the two-triangle carrier SPWM are not much different.
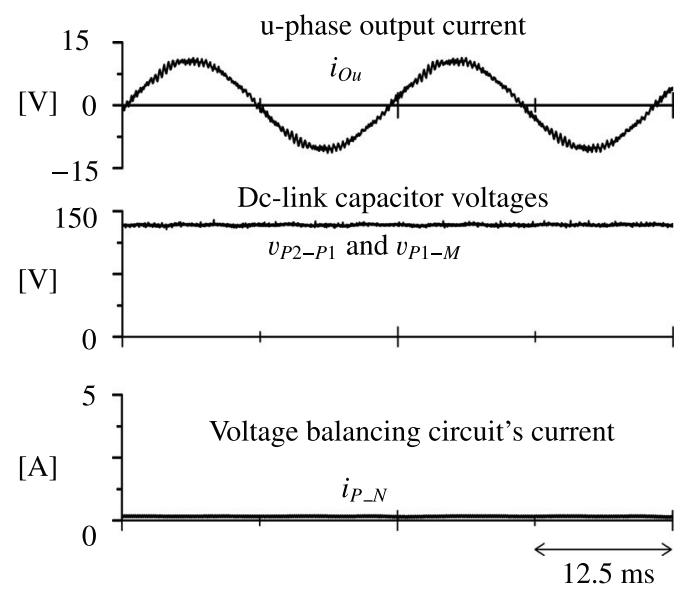

Fig. 18. Experimental waveforms of the voltage balancing circuit (buck converter) with the two-carrier SPWM based five-level diode-clamped PWM inverter when the modulation index was 1.0 , output power was $3.2 \mathrm{~kW}$, and output frequency was $41.6 \mathrm{~Hz}$
However, the five-level inverter with the two-triangle carrier SPWM has better results than the NPC inverter, especially, for the high frequency harmonics.

Figure 20 compares the u-phase output current harmonics and THD of the experimental systems. The five-level inverter with original SPWM gives the best result. The five-level inverter with the two-triangle carrier SPWM has THD a bit lower than that of the NPC inverter.

Table 3 summarizes the overall characteristics of the NPC PWM inverter, the original SPWM-based five-level diodeclamped inverter, and the two-triangle carrier SPWM based five-level diode-clamped inverter. We can see that the fivelevel inverter with the two-triangle carrier SPWM has its merits and demerits in the middle between those of the NPC inverter and the original SPWM based five-level inverter. Some benefits of the proposed technique bring more interesting points such as more output voltage step has an advantage of using in long cable motor drive systems. Especially, the delay time ( $T_{d 1}$ and $T_{d 2}$ ) of the proposed technique would be defined for minimizing motor terminal overvoltage caused by long cable ${ }^{(30)(31)}$. However, this issue is beyond the scope of this paper. The detail is not discussed in this paper.

\section{Conclusion}

This paper introduced the two-triangle carrier SPWM for the five-level diode-clamped PWM inverter and compared its characteristics with those of the NPC PWM inverter and the original SPWM-based five-level diode-clamped PWM inverter. It was found that the performance of the two-triangle carrier SPWM based five-level inverter has benefits in between those of the NPC inverter and the original SPWMbased five-level inverter, while the cost and power loss are nearly the same as that of the NPC inverter. The two-triangle carrier SPWM would be an interesting candidate for mediumvoltage applications.
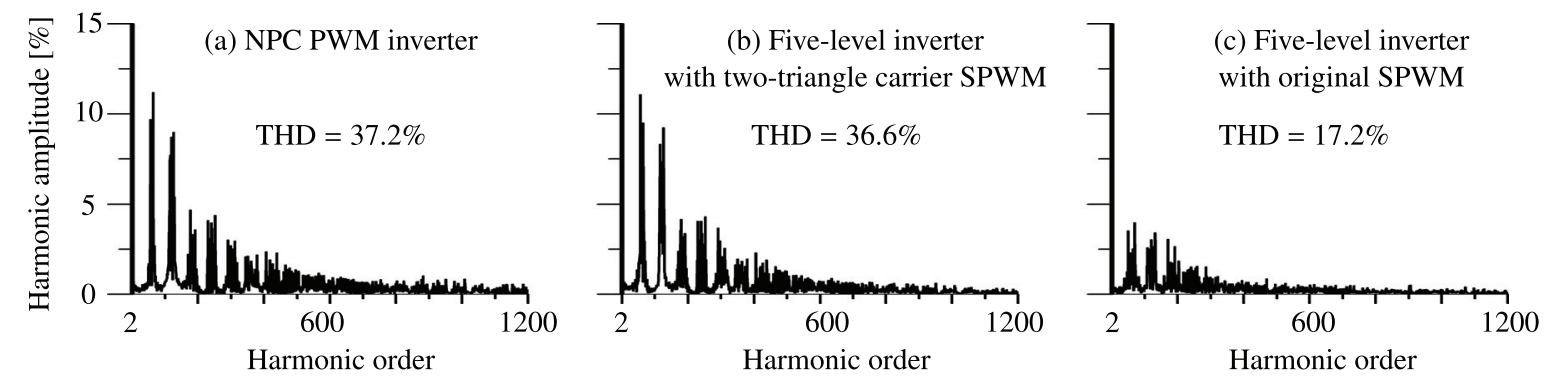

Fig. 19. Harmonics of line-to-line output voltage when the modulation index was 1.0, output power was $3.2 \mathrm{~kW}$, and output frequency was $41.6 \mathrm{~Hz}$
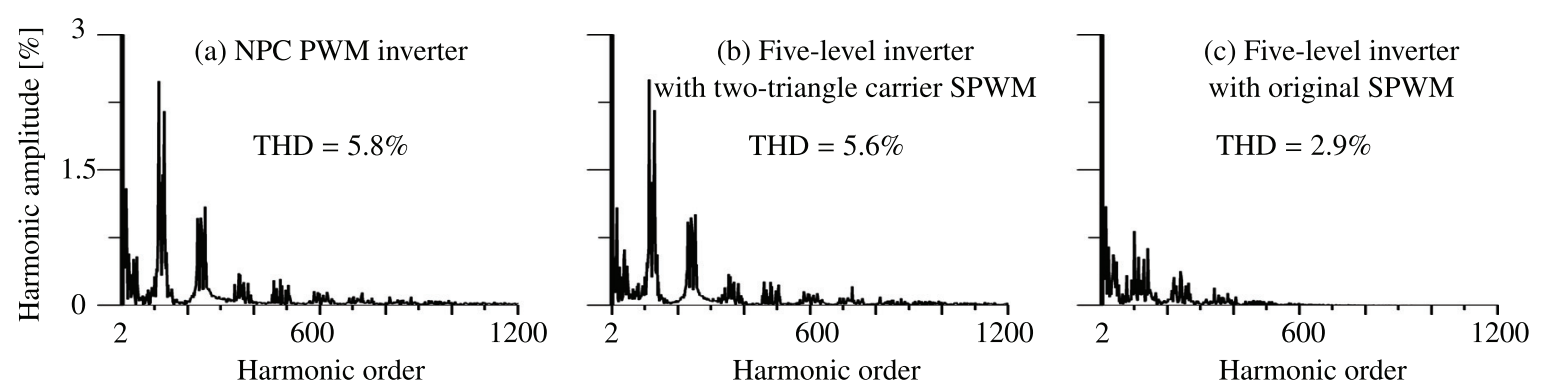

Fig. 20. Harmonics and THD of u-phase output current when the modulation index was 1.0, output power was $3.2 \mathrm{~kW}$, and output frequency was $41.6 \mathrm{~Hz}$ 
Two-Triangle Carrier Modulation For a Five-Level Inverter (Natchpong Hatti et al.)

Table 3. Comparison of the inverter systems

\begin{tabular}{l||l|l|l}
\hline & NPC inverter & $\begin{array}{l}\text { Five-level inverter } \\
\text { with original SPWM }\end{array}$ & $\begin{array}{l}\text { Five-level inverter } \\
\text { with two-triangle carrier SPWM }\end{array}$ \\
\hline \hline Number of switching devices & $\begin{array}{l}24 \\
(2 \text { switching devices connected } \\
\text { in series for each switch) }\end{array}$ & 24 & 24 \\
\hline$d v / d t$ & High & Low & Low \\
\hline Output voltage THD & High & Low & High \\
\hline Series connection of switching devices & Required & Not required & Not required \\
\hline Gate drivers & Complex & Simple & Simple \\
\hline Output voltage step (Lower is better) & High & Low & Low \\
\hline $\begin{array}{l}\text { Total power rating of voltage balancing circuits } \\
\text { (Including buck and boost converters) }\end{array}$ & Non & $14 \%$ of the motor power rating & $1 \%$ of the motor power rating \\
\hline Current rating of clamping diodes & $\begin{array}{l}\text { Normal } \\
(\text { D1\&D2 in Fig. 1) }\end{array}$ & $\begin{array}{l}\text { Normal } \\
(\mathrm{D} 1-\mathrm{D} 6 \text { in Fig. } 4)\end{array}$ & $\begin{array}{l}\text { Normal for D3\&D4 } \\
\text { Very low for D1, D2, D5, D6 } \\
\text { (in Fig. 4) }\end{array}$ \\
\hline Switching power loss & High & Low & High \\
\hline Switching frequency [Hz] & $0.5 f_{C}$ for all switches & $\begin{array}{l}f_{S 1}=0-0.4 f_{C} \\
f_{S 2}=0.1 f_{C}-0.5 f_{C}\end{array}$ & $0.5 f_{C}$ for all switches \\
\hline Phase voltage step & 3 & 5 & 5 \\
\hline Line-to-line voltage step & 5 & 9 & 9 \\
\hline
\end{tabular}

Note: $f_{S 1}$ is the switching frequency of $\mathrm{T} 2, \mathrm{~T} 3, \mathrm{~T} 6$, and $\mathrm{T} 7 . f_{S 2}$ is the switching frequency of $\mathrm{T} 1, \mathrm{~T} 4, \mathrm{~T} 5$, and $\mathrm{T} 8 .{ }^{(20)}$

\section{References}

(1) A. Nabae, I. Takahashi, and H. Akagi: "A new neutral-point-clamped PWM inverter", IEEE Trans. Ind. Appl., Vol.17, pp.518-523 (1981)

( 2 ) J. Rodriguez, S. Bernet, P.K. Steimer, and I.E. Lizama: "A survey on neutral-point-clamped inverters", IEEE Trans. on Ind. Electron., Vol.57, No.7, pp.2219-2230 (2010)

( 3 ) S. Malik and D. Kluge: "ACS 1000 world's first standard ac drive for medium-voltage applications", ABB Review, No.2, pp.4-11 (1998)

( 4 ) J.S. Lai and F.Z. Peng: "Multilevel converters-A new breed of power converters", IEEE Trans. Ind. Appl., Vol.32, No.3, pp.509-517 (1996)

( 5 ) J. Rodriguez, J.S. Lai, and F.Z. Peng: "Multilevel inverter: A survey of topologies, control, and applications", IEEE Trans. Ind. Electron., Vol.49, No.4, pp.724-738 (2002)

( 6 ) B. Wu: High-power converters and AC drives. IEEE Press (2006)

( 7 ) S. Ogasawara and H. Akagi: "Analysis of variation of neutral point potential in neutral-point-clamped voltage source PWM inverters", Conf. Rec. IEEEIAS Annu. Meeting, Vol.2, pp.965-970 (1993)

( 8 ) H. Fujita, S. Tominaga, and H. Akagi: "Analysis and design of a dc voltagecontrolled Static var compensator using quad-series voltage-source inverters", IEEE Trans. on Ind. Appl., Vol.32, No.4, pp.970-978 (1996)

( 9 ) S. Srianthumrong and H. Akagi: "A medium-voltage transformerless ac/dc power conversion system consisting of a diode rectifier and a shunt hybrid filter", IEEE Trans. Ind. Appl., Vol.39, No.3, pp.874-882 (2003)

(10) R.M. Tallam, R. Naik, and T.A. Nondahl: "A carrier-based PWM scheme for neutral-point voltage balancing in three-level inverters", IEEE Trans. Ind. Appl., Vol.41, No.6, pp.1734-1743 (2005)

(11) H. Akagi and T. Hatada: "Voltage-balancing control for a three-level diodeclamped converter in a medium-voltage transformerless hybrid active filter", IEEE Trans. on Power Electron., Vol.24, No.35, pp.571-579 (2009)

(12) M. Bruckmann, R. Sommer, M. Fasching, and J. Sigg: "Series connection of high voltage IGBT modules", IEEE IAS Conf., pp.1067-1072 (1998)

(13) P.R. Palmer and A.N. Githiari: "The series connection of IGBT's with active voltage sharing”, IEEE Trans. on Power Electronics, Vol.12, No.4, pp.637644 (1997)

(14) A.M. Massound, S.J. Finney, and B.W. Williams: "Multilevel converters and series connection of IGBT evaluation for high-power, high-voltage applications", IEEE PEMD Conf., Vol.1, No.498 (2004)

(15) C. Newton and M. Sumner: "Novel technique for maintaining balanced internal DC link voltages in diode clamped five-level inverters", in Proc. IEE Power Appl., Vol.146, No.3, pp.341-349 (1999)

(16) X. Yuan and I. Barbi: "Fundamentals of a New Diode Clamping Multilevel Inverter", IEEETrans. on Power Electronics, Vol.15, No.4, pp.711-718 (2000)

(17) Z. Pan, F.Z. Peng, K.A. Corzine, V.R. Stefannovic, J.M. Leuthen, and S. Gataric: "Voltage balancing control of diode-clamped multilevel rectifier/inverter systems", IEEE Trans. on Ind. Appl., Vol.41, No.6, pp.16981706 (2005)
(18) N. Hatti, Y. Kondo, and H. Akagi: "Back-to-back connected five-level diodeclamped PWM converters for motor drives”, IEEE Ind. App., Vol.44, No.4, pp.1268-1276 (2008)

(19) H. Akagi, H. Fujita, S. Yonetani, and Y. Kondo: "A 6.6-kV transformerless STATCOM based on a five-level diode-clamped PWM converter: System design and experimentation of a 200-V, 10-kVA laboratory model", IEEE Trans. Ind. Appl., Vol.44, No.2, pp.672-680 (2008)

(20) N. Hatti, K. Hasegawa, and H. Akagi: "A 6.6-kV transformerless motor drive using a five-level diode-clamped PWM inverter for energy savings of pumps and blowers", IEEE Trans. on Power Electron., Vol.24 No.3, pp.841-852 (2009)

(21) K. Hasegawa and H. Akagi: "A new dc-voltage-balancing circuit including a single coupled inductor for a five-level diode-clamped PWM inverter", IEEE Trans. on Industry Application, Vol.47, No.2, pp.841-852 (2011)

(22) M. Marchesoni and P. Tenca: "Diode-clamped multilevel converters: A practicable way to balance DC-link voltages", IEEE Trans. on Ind. Electron., Vol.49, No.4, pp.752-765 (2002)

(23) S. Busquets-Monge, S. Alepuz, J. Bordonau, and J. Peracaula: "Voltage balancing control of diode-clamped multilevel converters with passive frontends", IEEE Trans. Power Electron., Vol.23, No.4, pp.1751-1758 (2008)

(24) A. Shukla, A. Ghosh, and A. Joshi: "Control schemes for DC capacitor voltages equalization in diode-clamped multilevel inverter based DSTATCOM", IEEE Trans. on Power Delivery, Vol.23, No.2, pp.1139-1149 (2008)

(25) H.A. Hotait, A.M. Massound, S.J. Finney, and B.W. Williams: "Capacitor voltage balancing using redundant states of space vector modulation for fivelevel diode clamped inverters", IET Power Electron., Vol.3, No.2, pp.292313 (2010)

(26) O. Bouhali, B. Francois, M. Berkouk, and C. Saudemont: "DC link capacitor voltage balancing in a three-phase diode clamped inverter controlled by a direct space vector of line-to-line voltages", IEEE Trans. on Power Electron., Vol.22, No.5, pp.1636-1648 (2007)

(27) J. Pou, R. Pindado, and D. Boroyevich: "Voltage-balance limits in four-level diode-clamped converters with passive front ends", IEEE Trans. on Ind. Electron., Vol.52, No.1, pp.190-196 (2005)

(28) N. Hatti: "Study of a five-level diode-clamped PWM inverter for mediumvoltage motor drives", PhD. Dissertation, Department of Electrical Engineering, Tokyo Institute of Technology, pp.938-103 (2009)

(29) N. Hatti, K. Hasegawa, and H. Akagi: "A modulation technique of FiveLevel Diode-Clamped PWM inverter for size reduction of voltage balancing circuit", (Written in Thai) EECON 32, Thailand (2009)

(30) S. Lee and K. Nam: "An overvoltage suppression scheme for AC motor drives using a half DC-link voltage level at each PWM transition", IEEE Trans. on Ind. Electron., Vol.49, No.3, pp.549-557 (2002)

(31) V. Naumanen, J. Korhonen, P. Silventoinen, and J. Pyrhonen: "Mitigation of high du/dt-originated motor overvoltages in multilevel inverter drives", IET Trans. on Power Electron., Vol.3, No.5, pp.681-689 (2010) 
Natchpong Hatti (Non-member) was born in Nakhon Si Thammarat,

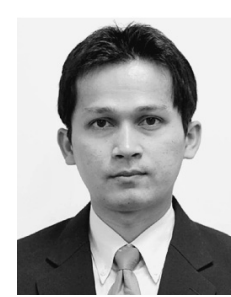
Thailand. He received the Bachelor degree in electronics technology from King Mongkut's Institute of Technology Ladkrabang, Thailand, in 1994, the M.E. degree in electrical engineering from King Mongkut's Institute of Technology, Bangkok, Thailand, in 2001, and the Ph.D. degree from Tokyo Institute of Technology, Japan, in 2009. He is now a Researcher in the Advanced Automation and Electronics Research Unit, National Electronic and Computer Technology Center (NECTEC), Thailand. His research interests are multilevel inverters, power converters, and renewable energy.

Surasak Nuilers (Non-member) was born in Songkhla, Thailand, in

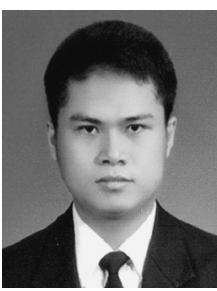

1986. He received the Bachelor Degree and the Master Degree of Science in Electrical Engineering from King Mongkut's University of Technology North Bangkok (KMUTNB), Thailand, in 2007 and 2010, respectively. He is now an Assistant Researcher in the Advanced Automation and Electronics Research Unit, National Electronic and Computer Technology Center (NECTEC), Thailand. His research interests include renewable energy power generation, UPS, multilevel converters and motor drive.
Jirayut Phontip (Non-member) was born in Udon Thani, Thailand,

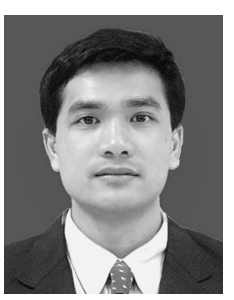
in 1977. He received the Bachelor Degree of Science in Electrical Engineering from King Mongkut's University of Technology North Bangkok (KMUTNB), Thailand, in 2001. He is now an Assistant Researcher in the Advanced Automation and Electronics Research Unit, National Electronic and Computer Technology Center (NECTEC), Thailand. His research interests include PV power generation and DC to DC converters. 